\title{
Enzymatic replacement therapy for lysosomal storage disorders: drug evaluations review
}

in Spain.

Darbà Josep ${ }^{1}$, Ascanio Meritxell ${ }^{2}$

${ }^{1}$ Universitat de Barcelona, Barcelona, Spain; ${ }^{2}$ BCN Health Economics \& Outcomes Research S.L., Barcelona, Spain

Correspondence to:

Josep Darbà

Department of Economics. Universitat de Barcelona, Diagonal 696, 08034 Barcelona, Spain Tel. +34 934020110 / + 34934021937

Fax +34934039082

E-mail darba@ub.edu

Funding: None.

Competing interests: None declared.

Ethical approval: Not required.

\section{ABSTRACT}

Introduction: In the European Union companies only need to demonstrate that the risk-benefit balance of the new drug is favourable to obtain the authorization to sell new drugs. Hence a comparison with available treatments, a cost-effectiveness analysis and the place in the therapy of the new drug are not required. Therefore, it is necessary to carry out these analyses in an additional study. In Spain there is no national government agency, which conducts a centralized evaluation and makes decisions on funding and are the Pharmacy and Therapeutics committees that take mandatory decisions for the entire region.

Objectives: To identify all drug assessments and health technology assessment reports of the enzymatic replacement treatments for the four LSD considered in this study, including Mucopolysaccharidosis (MPS), Gaucher, Fabry and Pompe disease at the national, regional and hospital level; and to summarize the efficacy in terms of outcome measures, adverse events, economic impact and final recommendations and indicate potential improvements.

Methods: 19 reviews at the regional and hospital level and one therapeutic positioning report at national level for MPS were considered for this. 
Results: In general, the drugs evaluated in LSD have demonstrated to be effective in the most frequent clinical forms of disease. However, there are clinical phenotypes that still do not have available an effective treatment.

Conclusions: It is expected that new therapies, such as intrathecal therapies or gene therapy could be evaluated in the different types of LSD demonstrating positive effects, especially in the previous phenotypes.

Keywords: lysosomal storage disorders; Mucopolysaccharidosis; Gaucher disease; Pompe disease; Fabry disease; enzymatic replacement therapy 


\section{INTRODUCTION}

More than 50 rare metabolic disorders caused by the accumulation of non-degraded substrates in lysosomes due to an enzymatic defect are considered lysosomal storage diseases (LSDs) [1]. The specific LSDs considered in this review are mucopolysaccharidosis (MPS) [2,3], Gaucher disease $[4,5]$, Pompe disease $[6,7]$ and Fabry disease $[8,9]$ which involve the accumulation of glycosaminoglycans, glucocerebrosides, glycogen and sphingolipids, respectively. Although most of the above mentioned diseases are autosomal recessively inherited, a fraction of them, such as Fabry disease and MPS type II, follow an X-linked recessive inheritance. Current treatment of LSDs in Spain is mostly centred on enzymatic replacement therapy (ERT).

In order to authorize the sale of a new drug in the European Economic Area (EEA), pharmaceutical companies are not required to provide evidence of the cost-effectiveness or place in the treatment of such drug [10]. A positive resolution can be obtained from national institutions or from the European Medicines Agency (EMA) through the risk-benefit balance of the therapy studied $[11,12]$.

This being the case, and due to the fact that most of the drugs that are available in Spain are funded by the public health service, further studies need to be developed to determine the drug's place in therapy and cost-effectiveness [13].

Health institutions and Pharmacy and Therapeutics Committees (PTCs) in distinct regions of Spain carry out drug evaluations and decision-making at the autonomic level. The results are described in Health Technology Assessment (HTA) reports containing specific recommendations, which may or may not be followed by hospital and prescribers [14].

The PTCs specifically evaluate those drugs that are dispensed by the hospital pharmacy service or are administered directly to patients. The used drugs are selected by means of phamacoeconomic, efficacy, efficiency and safety relevance in comparison to the alternative drugs in the market and included in the hospital formulary [15].

Additionally, the Spanish Agency of Medicines and Health Products (AEMPS), which is associated to the national health ministry implements baseline evaluations regarding effectiveness, appropriate use and efficiency of the therapeutics according to legislation and carries out budget management and standardization at a national level. This information is displayed in Therapeutic Positioning Reports (TPR). 
This study has two different objectives: 1) to identify all drug assessments and health technology assessment (HTA) reports of the current treatment for the four LSD considered in this study, including Mucopolysaccharidosis (MPS), Gaucher disease, Fabry disease and Pompe disease at the national, regional and hospital level; 2) to summarize the efficacy in terms of outcome measures, adverse events, economic impact and final report recommendations and indicate potential improvements.

\section{MATERIAL AND METHODS}

Health technology assessments (HTA) and therapeutic positioning reports (TPR) published since 2004 were obtained from two different sources, GENESIS [16], a group of evaluation of novelties, standardization and research in drug selection, belonging to the Spanish Society of Hospital Pharmacy, and AEMPS [17], the Spanish Agency of Medicines and Health Products, respectively. A database was constructed in order to analyse and summarize parameters of interest by means of an indirect comparison.

The reports included in this analysis assess the current ERT for treatment of LSD except for one report assessing substrate reduction therapy (SRT) for Gaucher type I disease. The final selected reports correspond to a total of 20 national therapeutic positioning reports and reviews at the regional and hospital level. Specifically, 8 for MPS [18-24], 5 for Gaucher disease [25-28], 4 for Fabry disease [29-31] and 2 for Pompe disease [32-33].

The following parameters were extracted from the reports: agency or hospital where the report has been written, drug name, active ingredient, drug presentations, posology and administration form, pharmaceutical company that commercializes the drug, price, report publication date, evaluated indication, Anatomical Therapeutic Chemical classification (ATC) code, Randomized controlled trial (RTC) methodology, RCTs comparators, primary outcomes measures, secondary outcomes measures, efficacy measures results, adverse events, report conclusions and recommendations.

\section{RESULTS}

The reports included in this analysis assess the current treatment of LSD. These correspond to 20 reviews at the regional and hospital level (Table 1). 


\section{Review of ERT evaluated in MPS}

\section{1) ELOSULFASE ALFA (VIMIZIM®)}

Elosulfase alfa has been evaluated as an ERT for the long term in patients with confirmed diagnostic of MPS type IV A in patients of all ages (Table 2). Considering the efficacy and safety results and according to the report conclusions, the treatment of MPS type IV A with elosulfase alfa has demonstrated to improve the functional capacity, based on the distance walked in the six-minute walking test in comparison with placebo, over a period of 24 weeks. Elosulfase alfa is generally well-tolerated among patients although it is important to control reactions related with infusion, anaphylactic reactions and development of antibodies against treatment.

The therapeutic positioning recommendations suggest controlling periodically the possible presence of antibodies anti-elosulfase alfa to corroborate if they are affecting the therapeutic efficacy. Moreover, treatment with elosulfase alfa should be re-evaluated when: 1) patients do not respond according to mobility, respiratory and cardiovascular parameters and quality of life; 2) absence of improvement in six-minute walking test after 1-year treatment and/or progression of bone affection that leads to the need of wheelchair in those patients in whom treatment has been initiated by criteria of impairment mobility; 3 ) in case of recurrent anaphylactic reaction, not easily controllable with usual medication.

\section{2) LARONIDASE (ALDURAZYME®)}

Laronidase has been evaluated as an ERT for the long term in patients with confirmed diagnostic of MPS type I (Table 3). Considering the efficacy and safety results and according to the report conclusions, laronidase has demonstrated to improve the respiratory function and physical capacity in comparison with placebo, over a period of 26 weeks. Moreover, the efficacy outcomes suggest that patients treated with laronidase present a decrease in hepatic volume and urinary glycosaminoglycans (GAG) concentration. These efficacy results are estimated to remain stable in the long term.

The therapeutic positioning recommendations suggest treatment with laronidase in patients who are: 1) <2 years with normal cognitive function and attenuated phenotype; 2) <2 years with normal cognitive function and severe physical impairment, as a previous treatment to HSCT; 3) <2 years with cognitive impairment; 4) >2 years without cognitive impairment; 5) >2 years with cognitive impairment, as palliative treatment. 


\section{3) GALSULFASE (NAGLAZYME®)}

Galsulfase has been evaluated as ERT for the long term in patients with confirmed diagnostic of MPS type IV (Table 4). Considering the efficacy and safety results and according to the report conclusions, galsulfase has demonstrated to improve the resistance of patients based on the measures of the distance walked in 12-minute walk test and the number of steps walked up in 3 minutes in comparison with placebo. Moreover, the efficacy outcomes suggest a significant decrease in urinary GAG concentration in patients treated with galsulfase and an improvement of pain and joint stiffness based on quality of life parameters.

The therapeutic positioning recommendations suggest treatment with galsulfase as an alternative therapeutic option to conventional treatment of MPS type IV. Given the safety profile of galsulfase, it is recommended to control patients during infusion due to the possible onset of anaphylactic reactions.

\section{4) IDURSULFASE (ELAPRASE®)}

Idursulfase has been evaluated as an ERT for the long term in patients with confirmed diagnostic of MPS type II (Table 5). Considering the efficacy and safety results and according to the report conclusions, idursulfase has demonstrated to improve the resistance and the respiratory capacity of patients based on the combined variable analysed in comparison with placebo. Moreover, the efficacy outcomes indicate that produces a significant reduction of the GAG concentration in urine, as well as contributes to decrease organomegaly.

The therapeutic positioning recommendations suggest treatment with idursulfase as an alternative therapeutic option to conventional treatment of MPS type II.

\section{Review of ERT evaluated in Gaucher disease}

\section{1) IMIGLUCERASE (CEREZYME®)}

Imiglucerase has been evaluated as an ERT for the long term in patients with confirmed diagnostic of type I Gaucher. Imiglucerase is also approved for treatment of type III Gaucher disease in patients who present non-neurologic manifestations that are clinically significant (Table 6). Considering the efficacy and safety results and according to the report conclusions, imiglucerase has demonstrated comparable results in terms of efficacy with regard to alglucerase, by increasing haemoglobin concentration and platelet count as well as reducing hepatic and splenic volumes. These efficacy outcomes are estimated to be stable in the long term. Moreover, 
different studies suggest that the clinical response obtained from this treatment is not different from that obtained in patients with Gaucher type III.

The therapeutic positioning recommendations suggest treatment with imiglucerase in paediatric population with diagnostic of disease at this age, except in Gaucher type II disease.

\section{2) VELAGLUCERASE (VPRIV®)}

Velaglucerase has been evaluated as ERT for the long term in patients with confirmed diagnostic of type I Gaucher (Table 7). Considering the efficacy and safety results and according to the report conclusions, velaglucerase has demonstrated comparable results in terms of efficacy with regard to imiglucerase, by increasing haemoglobin concentration and platelet count as well as reducing hepatic and splenic volumes. This efficacy outcomes are estimated to be stable in the long term even if the dose is reduced a $50 \%$.

The therapeutic positioning recommendations suggest that given the similar efficacy and safety profile of velaglucerase and imiglucerase, the selection of treatment between both drug formulations should take into account efficiency criteria.

\section{3) MIGLUSTAT (ZAVESCA®)}

Miglustat has been evaluated as substrate reduction therapy (SRT) for the long term under exceptional conditions in patients with confirmed diagnostic of mild or moderate type I Gaucher disease who cannot or do not wish to receive ERT. Miglustat is also approved for paediatric and adult patients with Niemann-Pick disease type C (Table 8). Considering the efficacy and safety results and according to the report conclusions, miglustat as a maintenance therapy has only demonstrated slight changes in organomegaly and hematologic parameters after an evaluation of 6 and 12 months. Moreover, it was found that the change of treatment from imiglucerase or miglustat + imiglucerase to miglustat as monotherapy resulted in a reduction of the platelet count. These results indicate that miglustat may be less effective than treatment with ERT.

The therapeutic positioning recommendations suggest the use of miglustat as a first choice drug in the following cases: 1) naive patients when ERT is contraindicated due to hypersensitivity or impossibility of intravenous use; 2) refractory patients or intolerant to ERT; 3) patients wellcontrolled in previous treatment with ERT, in whom it is decided to change treatment to miglustat as monotherapy due to the improvements in quality of life associated with the oral treatment.

\section{Review of ERT evaluated in Fabry disease}




\section{1) AGALSIDASE ALFA (REPLAGAL®)}

Agalsidase has been evaluated alfa as ERT for the long term in patients with confirmed diagnostic of Fabry disease (Table 9). Considering the efficacy and safety results and according to the report conclusions, agalsidase alfa has demonstrated to reduce the neuropathic pain of maximum intensity and also the cardiac deposits of globotriaosylceramide (GL3) in comparison with placebo. It has been found also a reduction in left ventricular hypertrophy. Moreover, it has been found that agalsidase alfa slightly differs in terms of efficacy from agalsidase beta, considering that both have demonstrated to stabilize disease progression, especially with regards to the renal function.

The therapeutic positioning recommendations suggest that given the similar efficacy and safety profile of agalsidase alfa and agalsidase beta, the selection of treatment between both drug formulations should take into account efficiency criteria.

\section{2) AGALSIDASE BETA (FABRAZYME®)}

Agalsidase beta has been evaluated as ERT for the long term in patients with confirmed diagnostic of Fabry disease (Table 10). Considering the efficacy and safety results and according to the report conclusions, agalsidase beta has demonstrated to clear the GL3 deposits in capillary endothelium of kidneys as well as to reduce these levels in heart and skin in comparison with placebo. It has been found also a reduction in left ventricular hypertrophy. Moreover, therapy with agalsidase beta slows progression of clinical results of renal, cardiac and cerebrovascular complications and death, based on a long term analysis of 30-36 months.

The therapeutic positioning recommendations suggest that given the similar efficacy and safety profile of agalsidase beta and agalsidase alfa, the selection of treatment between both drug formulations should take into account efficiency criteria.

\section{Review of ERT evaluated in Pompe disease}

\section{1) ALGLUCOSIDASE ALFA (MYOZYME®)}

Alglucosidase alfa has been evaluated as ERT for the long term in patients with confirmed diagnostic of Pompe disease in adult patients and paediatric population (Table 11). Considering the efficacy and safety results and according to the report conclusions, alglucosidase alfa has demonstrated to improve with a modest efficacy the functional capacity and to stabilize lung 
function, based on the variables of six-minute walk test and FVC in comparison with placebo, over a period of 78 weeks. Moreover, the efficacy outcomes suggest that this drug is more effective in the subgroups of patients with mild or moderate disease. It is worth mentioning that the maximum benefit of treatment has been observed during the first 26 weeks and afterwards the efficacy is stabilized.

The therapeutic positioning recommendations suggest that given the efficacy profile of alglucosidase alfa, it is estimated that the objective of treatment is prevention of loss tissue and muscular function. Therefore, patients in advanced stages of disease who present an irreversible affection of fibres and muscular tissues and with a limited repair capability of the impaired tissues cannot have benefit from treatment with alglucosidase alfa. Moreover, the safety profile of alglucosidase alfa should be evaluated in the long term in order to control the possible anaphylactic reactions potentially mortal.

\section{CONCLUSIONS}

The evaluation reports of ERT have drawn conclusions about its efficacy in treatment for the four different LSD considered in this study. However, it is difficult to determine exactly its clinical effect, considering that LSD diseases are related to a progressive organ and tissue involvement that causes heterogeneous clinical symptoms.

In patients with MPS, galsulfase, laronidase and idursulfase have demonstrated to improve the resistance and respiratory capacity and the last two, to reduce the GAG concentration in urine and organomegaly in the short term. Less robust data has been found for elosulfase alfa, which benefit is based on the six-minute walk test.

In patients with Gaucher disease type I, imiglucerase and velaglucerase have shown increasing haemoglobin concentration and platelet count as well as reducing hepatic and splenic volumes in the short and long term. Miglustat has only demonstrated slight changes in organomegaly and hematologic parameters as well as a minor efficacy in comparison with ERT.

In patients with Fabry disease, agalsidase alfa and beta have demonstrated similar efficacy in reduction of the cardiac deposits of GL3 and the left ventricular hypertrophy and stabilization of renal function, in the short term. Agalsidase beta also reduces the GL3 levels in kidney and skin and can slow the progression to renal, cardiac and cerebrovascular complications and death, based on a long-term analysis [22]. 
In patients with late-onset Pompe disease, alglucosidase alfa has demonstrated to improve the functional capacity and to stabilize lung function with modest efficacy. An analysis per subgroups indicates there is a higher efficacy in patients with mild or moderate disease.

Regarding the safety profile of the ERT evaluated in LSD, the main adverse events are reactions associated with the administration of the drug and the development of antibodies against treatment. In the case of SRT, adverse reactions are more related to gastrointestinal disorders and neurologic events.

Regarding the economic impact of the evaluated drugs, it is estimated these are very expensive treatments, highlighting that idursulfase and galsulfase are two of the most expensive drugs. Taking into consideration the high cost of these treatments, in addition to a lack of evidence on the impact in quality of life and evolving of neurologic disease, it would be necessary to define the conditions of indication of these drugs, based on a group of experts.

\section{Future perspectives}

In order to enhance decision-making and accurate recommendations and indications, future drug assessments should be able to present further evidence regarding cost-effectiveness and place in treatment. To do so studies should include direct comparisons regarding alternative current therapies and more significant or clinically relevant outcome measures. Real world data studies regarding the use of therapeutics would add value to reports and would be useful in terms of recommendations updates. 


\section{FINANCIAL \& COMPETING INTERESTS DISCLOSURE}

The authors have no relevant affiliations or financial involvement with any organization or entity with a financial interest in or financial conflict with the subject matter or materials discussed in the manuscript apart from those disclosed.

No writing assistance was utilized in the production of this manuscript. 


\section{REFERENCES}

1. Parenti G, Andria G, Ballabio A. Lysosomal Storage Diseases: From Pathophysiology to Therapy. Annu Rev Med. 66, 471-486 (2015).

2. Dalmau J, Guillén E, Pérez J, Couce ML, González L, Aldamíz L. Guía para el manejo de las MPS. Ergon, Madrid, Spain (2015).

3. Aguirre Rodríguez FJ, Aldámiz-Echevarría Azuara L, Dalmau Serra J et al. Guía clínica de la mucopolisacaridosis tipo I (MPS I). Mayo, Barcelona, Spain (2014).

4. Giraldo P, Pocoví M. Guía de actuación en pacientes con enfermedad de Gaucher. FEETEG, Zaragoza, Spain (2011).

5. Baldellou A, Dalmau J, Sanjurjo P. Guía clínica para el diagnóstico, tratamiento y seguimiento de la enfermedad de Gaucher en la infancia. Acta Pediatr. Esp. 64, 175-180 (2006).

6. Pascual-Pascual SI, Nascimento A, Fernández-Llamazares CM et al. Guía clínica de la enfermedad de Pompe infantil. Rev Neurol. 63(6), 269-279 (2016).

7. Barba-Romero MA, Barrot E, Bautista-Lorite $\mathrm{J}$ et al. Guía clínica de la enfermedad de Pompe de inicio tardío. Rev Neurol. 54, 497-507 (2012).

8. García de Lorenzo A. Consensus for the study and treatment of Fabry disease. GETER Foundation. Med Clin (Barc). 137(4), 178-183 (2011).

9. Grupo para el Estudio y Tratamiento de la Enfermedad de Fabry (GETEF). Guía clínica para el Estudio y Tratamiento de la Enfermedad de Fabry. Enfermedades raras.(2005).

10. European Medicines Agency (EMA). European Medicines Agency (EMA) - About us. (2018).

http://www.ema.europa.eu/docs/en_GB/document_library/Other/2016/08/WC500211862.pdf

11. European Parliament, Council of the European Union. Directive 2004/27/EC of the European Parliament and of the Council of 31 March 2004 amending Directive 2001/83/EC on the Community code relating to medicinal products for human use (Text with EEA relevance). Official Journal L 136. (2004).

12. AEMPS. Cómo se regulan los medicamentos y productos sanitarios en España [How are medicines and health products regulated in Spain?]. (2017). 
https://www.aemps.gob.es/publicaciones/publica/regulacion_med-PS/v2/docs/reg_med-PSv2-light.pdf.

13. Álvarez JS. Utilidad terapéutica y social de los medicamentos: ¿cómo evaluarla y cuantificarla? [Therapeutic and social usefulness of medicines: how can it be evaluated and quantified?]. Medicina Clínica. 132(3) (2009).

14. GENESIS Grup. Normativas sobre selección de medicamentos y Comissiones de Farmacia y Terapéutica en comunidades autónomas [Regulation for medicine selection and FTCs in autonomous communities]. (2018).

https://gruposdetrabajo.sefh.es/genesis/index.php?option=com_content\&view=article\&id=5 $1 \&$ Itemid $=30$.

15. Lozano-Blázquez A, Calvo-Pita C, Carbajales-Álvarez M, Suárez-Gil P, Martínez-Martínez F, Calleja-Hernández MÁ. Drug assessment by a Pharmacy and Therapeutics committee: from drug selection criteria to use in clinical practice. Dovepress, 10 (2011).

16. GENESIS website.

http://gruposdetrabajo.sefh.es/genesis/genesis/Enlaces/InformesHosp_abc.htm.

17. AEMPS website.

https://www.aemps.gob.es/medicamentosUsoHumano/informesPublicos/home.htm.

18. Real JM, Palomo P, García-Jiménez MC. Genesis Group. Laronidasa en Mucopolisacaridosis tipo I. (2010). http://www.sefh.es/sefhgrupotrabajo/gt-accesogenesis.php?file=Laronidasa_HUMS_10_2010.doc.

19. AIAQS. Tratamiento de sustitución enzimática en pacientes con mucopolisacaridosis I, II y VI. (2009). http://aquas.gencat.cat/web/.content/minisite/aquas/publicacions/2011/pdf/mucopolisacarid osis_enzim_pcsns09_aiaqs2011.pdf.

20. CAMUH. Galsulfasa (Naglazyme®) per al tractament de la mucopolisacaridosi VI. (2010). http://aquas.gencat.cat/web/.content/minisite/aquas/publicacions/2010/pdf/galsulfasa_muco polisacaridosivi_aatrm2010ca.pdf.

21. CAMUH. Idursulfasa (Elaprase®) per al tractament de la mucopolisacaridosi II. (2010). http://aquas.gencat.cat/web/.content/minisite/aquas/publicacions/2010/pdf/idursulfasa_muc opolisacaridosi_aatrm2010ca.pdf. 
22. CAMUH. Laronidasa (Aldurazyme®) per al tractament de la mucopolisacaridosi I. (2010). http://aquas.gencat.cat/web/.content/minisite/aquas/publicacions/2010/pdf/laronidasa_muco polisacaridosi_aatrm2010ca.pdf.

23. Hospital Virgen del Rocío. Informe sobre laronidasa en el tratamiento de mucopolisacaridosis I. (2005). http://gruposdetrabajo.sefh.es/genesis/genesis/Documents/laronidasa_huvr_10_05.doc.

24. AEMPS. Informe de Posicionamiento Terapéutico de elosulfasa alfa (Vimizim®). (2016). https://www.aemps.gob.es/medicamentosUsoHumano/informesPublicos/docs/IPTelosulfasa-alfa-Vimizim-Mucopolisacaridosis.pdf.

25. CAMUH. Imiglucerasa en pacients amb malaltia de Gaucher tipus III. (2013). http://aquas.gencat.cat/web/.content/minisite/aquas/publicacions/2013/pdf/imiglucerasa_ga ucher_aiaqs2013ca.pdf.

26. CAMUH. Tractament de substitució enzimàtica per a pacients amb malaltia de Gaucher tipus I. (2011). http://aquas.gencat.cat/web/.content/minisite/aquas/publicacions/2011/pdf/tse_gaucher_imi velaglucerasa_aiaqs2011ca.pdf.

27. CAMUH. Miglustat (Zavesca®) per a pacients amb malaltia de Gaucher tipus I. (2011). http://aquas.gencat.cat/web/.content/minisite/aquas/publicacions/2011/pdf/miglustat_gauch er_aiaqs2011ca.pdf.

28. Hospital Virgen del Rocío. Informe sobre miglustat en el tratamiento de la enfermedad de Gaucher tipo I. (2004). gruposdetrabajo.sefh.es/genesis/genesis/Documents/miglustat_hvr_05_04.doc.

29. CAMUH. Agalsidasa alfa (Replagal®) i agalsidasa beta (Fabrazyme®) per al tractament de pacients amb malaltia de Fabry. (2012). http://aquas.gencat.cat/web/.content/minisite/aquas/publicacions/2012/pdf/agalsidasa_alfa_ beta_fabry_aiaqs2012.pdf.

30. Hospital Morales Meseguer. Agalsidasa alfa y beta en la Enfermedad de Fabry. (2008). http://gruposdetrabajo.sefh.es/genesis/genesis/Documents/Agalsidasa_HMM_1208.doc. 
31. Schiffmann R, Ries M, Timmons M, Flaherty JT, Brady RO. Long-term therapy with agalsidase alfa for Fabry disease: safety and effects on renal function in a home infusion setting. Nephrol Dial Transplant. 21: 345-354 (2006).

32. AETSA. Alglucosidasa alfa (Myozyme®) en enfermedad de Pompe de comienzo tardío. (2012).

http://www.juntadeandalucia.es/salud/servicios/contenidos/nuevaaetsa/up/AETSA_3_2012_ Alglucosidasa_Pompe.pdf.

33. CAMUH. Alglucosidasa alfa (Myozyme®) per al tractament de pacients amb formes tardanes de la malaltia de Pompe. (2011).

http://aquas.gencat.cat/web/.content/minisite/aquas/publicacions/2011/pdf/alglucosidasa_alf a_pompe_aiaqs2011ca.pdf. 